\title{
Deeper Protein Identification by using FAIMS in Top-Down Proteomics
}

Vincent R Gerbasi ${ }^{1,2, \ddagger}$, Rafael D Melani ${ }^{1, \ddagger}$, Susan E Abbatiello ${ }^{3,4}$, Michael W Belford ${ }^{4}$, Romain Huguet $^{4}$, John P McGee ${ }^{1}$, Dawson Dayhoff ${ }^{1}$, Paul M Thomas ${ }^{1}$, and Neil L Kelleher ${ }^{1 *}$

1. Northwestern University National Resource for Translational and Developmental Proteomics, Evanston, IL 60208

2. Pacific Northwest National Labs, Richland, WA 99352

3. Northeastern University, Boston, MA 02115

4. Thermo Fisher Scientific, San Jose, CA 98665

\$These authors contributed equally.

*Corresponding author: n-kelleher@ northwestern.edu

KEYWORDS Top-down proteomics, CD3 T cells, FAIMS, DMS, Tribrid mass spectrometer.

ABSTRACT. Field Asymmetric Ion Mobility Spectrometry (FAIMS), when used in proteomics studies, provides superior selectivity, and enables more proteins to be identified by providing additional gas phase separation. Here, we tested the performance of cylindrical FAIMS for the identification and characterization of proteoforms by top-down mass spectrometry of heterogeneous protein mixtures. Combining FAIMS with chromatographic separation resulted in a $62 \%$ increase in protein identifications and an $\mathbf{8 \%}$ increase in proteoform identifications as compared to samples analyzed without FAIMS. This increase was attributable, in part, to improved signal-to-noise for proteoforms with similar retention times. Additionally, our results show that the optimal compensation voltage of any given proteoform was correlated with the molecular weight of the analyte. 


\section{Collectively these results suggest that the addition of FAIMS can enhance top-down proteomics in both discovery and targeted applications.}

\section{INTRODUCTION}

Mass spectrometry (MS) based proteomics relies on separation of peptides and proteins, as extracts from cells, tissues and fluids create highly complex mixtures. Due to proteome heterogeneity, multidimensional separations are critical to reduce sample complexity prior to tandem $\mathrm{MS}^{1-3}$. For molecules of analytes to be sampled for fragmentation in a standard, "data-dependent" mode, its precursor intensity must be above the chemical/instrumental background noise and be one of the more abundant targets being measured ${ }^{1}$. Moreover, separation of molecular species occurring at similar mass-to-charge ratios is essential for the acquisition of non-chimeric fragmentation spectra to achieve unambiguous, efficient protein identification by database retrieval. Frequently, the separation technique used online with MS for proteomics is liquid chromatography (LC) because of its versatility and high peak capacity ${ }^{4}$.

Multi-dimensional chromatographic separation of digested peptide species helped usher in the technology underlying bottom-up proteomics (BUP) ${ }^{5,6}$. By combining more than one chromatographic separation method, techniques like MudPIT increased the number of protein identifications by reducing spectral heterogeneity ${ }^{5,6}$. While this technique has been promulgated internationally, similar platforms for in-line top-down proteomics (TDP) analysis of intact proteins have remained in a less developed state. Off-line separation of proteins prior to LC, dramatically increases the number of protein identifications in top-down experiments ${ }^{3}$. One technique that could enable multidimensional on-line protein separation for TDP analysis is Field Asymmetric Ion Mobility Spectrometry (FAIMS) ${ }^{7}$ after LC separation and prior to MS analysis, circumventing the limitations faced by multiple hyphenated on-line or off-line fractionation steps $^{3}$. 
Cylindrical FAIMS is a gas-phase fractionation approach that transmits ions based on their differential mobility in high and low electric fields ${ }^{7-11}$. In the context of a typical TDP experiment, intact proteins are ionized by an electrospray source and enter the FAIMS device, composed of an inner and outer electrode $^{7}$. A dispersion voltage provides an asymmetric waveform that propels ions towards one of the electrodes. Collision with either of the electrodes halts unstable ions, preventing their introduction to the mass spectrometer. Application of different compensatory DC voltages (compensation voltage, or CV) to the inner electrode of the FAIMS modifies the mobility of proteins, allowing them to pass through the FAIMS for detection? ${ }^{7}$ Hence, FAIMS can function as a gas-phase separation device for intact protein ions.

Prior utilization of FAIMS has improved peptide identification for BUP applications ${ }^{12,13}$ and functions primarily through improving analyte signal-to-noise ${ }^{14-16}$. Its use in TDP analysis has been limited, with most investigators studying intact protein standards. Investigators employing ion-mobility-time-offlight mass spectrometry systems have shown that IMS influences the arrival time distribution of different peptides, denatured protein charge states and multimeric native protein structures ${ }^{17-20}$ Our previous study employed static electrospray ionization (ESI) coupled with a commercial implementation of FAIMS to separate and analyze a simple mixture of heavy and light chains from a monoclonal antibody ${ }^{21}$. Without gas-phase fractionation, the light chain dominates the precursor ion signal in MS experiments, resulting in low signal-to-noise and poor detection of the heavy chain. Utilization of FAIMS prior to MS resolved the two antibody chains by favoring the FAIMS stability of the heavy or light chain of the antibody while suppressing the other, all as a function of the applied compensation voltage ${ }^{21}$. Additionally, combining liquid extraction surface analysis (LESA) with FAIMS provided a clear improvement in signal-to-noise of intact precursor ion signal compared to the same LESA samples analyzed without FAIMS ${ }^{22-26}$. Building from these initial observations of complex protein samples, we sought to characterize denatured proteoforms from complex protein samples using LC-FAIMS-MS/MS. The goal of the present study was to 
test and benchmark the performance of cylindrical FAIMS during TDP analysis of heterogeneous protein mixtures on an Orbitrap Fusion Lumos mass spectrometer. Our results show that combining FAIMS with reversed-phase LC separation enhances the number of both identified proteins and characterized proteoforms.

\section{METHODS}

Sample preparation: Top-down standard (TDS) was prepared following the instructions from the National Resource for Translational and Developmental Proteomics (NRTDP) http://nrtdp.northwestern.edu/protocols/. Primary human CD3+ T cells were obtained from STEMCELL Technologies.

Cell lysate samples were prepared as described previously ${ }^{27}$. Briefly, $1 \times 10^{9}$ cells were lysed in 1 $\mathrm{mL}$ of lysis buffer (20 mM Tris (pH 7.5), $100 \mathrm{mM} \mathrm{NaCl}, 1 \%$ (w/vol) N-laurylsarcosine, $1 \mathrm{mM} \mathrm{MgCl}_{2}$, and 1x Halt Inhibitor Cocktail (EDTA free) in distilled water). The lysate was treated with 1,500 units of benzonase nuclease (Sigma-Aldrich) for $15 \mathrm{~min}$. at room temperature, precipitated with four volumes of ice-cold acetone, and placed at $-80^{\circ} \mathrm{C}$ for $30 \mathrm{~min}$. Samples were centrifuged at $21,000 \times \mathrm{g}$ for 10 minutes at $4^{\circ} \mathrm{C}$, the acetone was removed, and the protein pellets were re-suspended in $1 \%$ SDS (w/v). Protein concentration was estimated using BCA protein assay kit (Thermo Fisher Scientific). Three-hundred micrograms of protein lysate was loaded onto 8\% GELFrEE (AbCam) cartridges per lane and electrophoresed following manufacturer's instructions. Fraction one containing the $0-30 \mathrm{kDa}$ proteins was precipitated using methanol-chloroform-water ${ }^{27}$. The protein pellets were then resuspended in $200 \mu \mathrm{L}$ of buffer A (0.2\% formic acid, $5 \%$ Acetonitrile, $\left.95 \% \mathrm{ddH}_{2} 0\right)$.

LC-FAIMS-MS/MS: Liquid chromatography (LC) was performed using $150 \mu \mathrm{m}$ i.d. x $3 \mathrm{~cm} \mathrm{~L}$

PLRP-S (5 $\mu \mathrm{m}$ particle, $1000 \AA$ pore size - Agilent Technologies) pre-column, to trap proteins, prior to fractionation over a $75 \mu \mathrm{m}$ i.d. x 14 cm L PLRP-S (5 $\mu \mathrm{m}$ particle, $1000 \AA$ pore size - Agilent Technologies) column using a 90-minute buffer B $\left(0.2 \%\right.$ formic acid, $95 \%$ Acetonitrile, $\left.5 \% \mathrm{ddH}_{2} 0\right)$ gradient. Separation 
was performed on a Dionex Ultimate 3000 (Thermo Fisher Scientific) under the following gradient: 5\% $\mathrm{B}$ at 10 min., $15 \% \mathrm{~B}$ at $12 \mathrm{~min} ., 55 \% \mathrm{~B}$ at $62 \mathrm{~min} ., 95 \% \mathrm{~B}$ from 67 to $72 \mathrm{~min} ., 5 \% \mathrm{~B}$ from 75 to $90 \mathrm{~min}$. LC was coupled online with FAIMS Pro (Thermo Fisher Scientific) interfaced with an Orbitrap Fusion Lumos (Thermo Fisher Scientific) mass spectrometer. Nitrogen was used as a carrier gas for FAIMS and no supplementary user-controlled carrier gas flow $(0 \mathrm{~L} / \mathrm{min})$ or $1 \mathrm{~L} / \mathrm{min}$. was used depending on the experiment. Compensation voltages (CV) were kept constant during each sample injection and chromatographic separation. CVs were adjusted in $10 \mathrm{~V}$ increments between replicate sample injections and ranged from $-70 \mathrm{~V}$ to $+30 \mathrm{~V}$. LC was online with the mass spectrometer for samples analyzed without the FAIMS Pro interface.

Precursor ion spectra were acquired in the Orbitrap analyzer at a resolving power setting of $120,000$ (at $\mathrm{m} / \mathrm{z}, 200)$, AGC was set to $1 \times 10^{6}$ charges/acquisition, with $200 \mathrm{~ms}$ of maximum injection time and four $\mu$ scans. Fragmentation of the top two most abundant spectra in data dependent mode were also acquired in the Orbitrap analyzer at a resolving power setting of 60,000 (at $\mathrm{m} / \mathrm{z} 200$ ). Precursors were quadrupole isolated used using a $3 \mathrm{~m} / \mathrm{z}$ isolation window, dynamic exclusion of $60 \mathrm{~s}$ duration, and threshold of $2 \times 10^{4}$ intensity. Target AGC values of $5 \times 10^{5}$ charges/acquisition, $800 \mathrm{~ms}$ of maximum injection time, and $4 \mu$ scans were used. Ions were fragmented using HCD at a setting of $23 \%$. In source collision induced dissociation was enabled at $15 \mathrm{~V}$ in all acquisition types.

Data analysis: The TD Portal platform v3.1 from NRTDP (https://portal.nrtdp.northwestern.edu/) operating on the Galaxy server was used to match top-down spectra to protein and proteoform targets from the database. Raw files were searched against the human proteome (UniProt release 2016_04). All protein and proteoform identifications were reported at a $1 \% \mathrm{FDR}^{28}$. Comparison of proteins and proteoforms identified with and without FAIMS was accomplished using TDViewer software (http://topdownviewer.northwestern.edu/) and using only identifications from Tight Absolute Mass and BioMarker search types. Venn diagram generators, R studio GGPlot2, and the TreeView clustering 
graphical user interface ${ }^{29}$ were also used to analyze the data. Raw files are available at massIVE under the identifier MSV000086748.

\section{RESULTS AND DISCUSSION}

Given past success using the FAIMS Pro interface to differentially fractionate reduced antibody chains in the gas-phase, we expanded the complexity of our analysis by testing the capacity of LC coupled to FAIMS to separate the four proteins present in the top-down standard (TDS) mixture. We performed replicate injections of TDS over 80 min. reversed-phase LC gradients with and without FAIMS prior to MS analysis. In samples that utilized FAIMS, we monitored the precursor ion signal in stepwise $10 \mathrm{~V}$ compensation voltage (CV) increments from $-30 \mathrm{~V}$ to $+20 \mathrm{~V}$ using no supplementary carrier gas flow. As expected, the injection without FAIMS showed all four proteins at their expected retention times consistent with previous studies ${ }^{30}$ (Figure 1, top panel). The most intense protein in the total ion chromatogram (TIC) was carbonic anhydrase $(29 \mathrm{kDa})$ followed by myoglobin $(16.7 \mathrm{kDa})$, and ubiquitin $(8.6 \mathrm{kDa})$ (Figure 1). Trypsinogen (24 kDa) was the least intense peak observed and eluted between ubiquitin and myoglobin. In the no-FAIMS analysis, the intensity of trypsinogen is typically lower relative to the more abundant TDS protein peaks in the chromatogram. Analysis of TDS with FAIMS and employing a CV of $-30 \mathrm{~V}$ resulted in a waveform that favored the stable trajectory of only ubiquitin as shown on the second panel of Figure 1. As the CV was increased by $10 \mathrm{~V}$ in subsequent $\mathrm{LC}$ injections, the remaining protein standards were observed with larger protein species generally preferring more positive CVs, consistent with previous observations $^{21}$ (Figure 1). The exception among the standards was trypsinogen, which contains disulfide bonds. Intriguingly, the folded structure of trypsinogen reduces the collisional cross section and affects the protein's trajectory during differential ion mobility in the gas phase compared to the other unfolded proteins; we observed trypsinogen to be stable at CVs $-20 \mathrm{~V}$ and $-10 \mathrm{~V}$ similar to that of the much smaller protein, myoglobin. 
During TDP analysis of complex protein mixtures, abundant proteins and proteoforms are detected at the expense of lower-abundance forms. The selective stability of TDS proteins at different CVs suggested that FAIMS may be useful as an orthogonal separation technique for proteoforms with retention times similar to more abundant co-eluting ions. As a model system for testing the behavior of heterogeneous protein populations in the LC-FAIMS-MS/MS system, we employed the 0-30 kDa protein fraction of whole cell extracts from a population of 20 million primary human $\mathrm{CD}^{+} \mathrm{T}$ cells afforded by employing an $8 \%$ GELFrEE cartridge ${ }^{27}$. Without supplementary carrier gas flow, we sought to identify the CVs that would result in the most proteoforms identified from a single injection ranging from $-40 \mathrm{~V}$ to $+30 \mathrm{~V}$. Figure $2 \mathrm{~A}$ demonstrates that the majority of the proteoforms were detected using a $\mathrm{CV}$ of $-20 \mathrm{~V}$ with a Gaussian-like distribution spanning between -40 and $+30 \mathrm{~V}$.

In BUP, the use of FAIMS Pro interface has been shown to increase the number of protein identifications when used as an orthogonal fractionation method ${ }^{12,13}$. Similarly, we tested if FAIMS separation would result in gains in protein or proteoform identifications. We compared eight replicate injections of $<30 \mathrm{kDa}$ proteins from $\mathrm{CD}^{+} \mathrm{T}$ cells without FAIMS to eight injections with FAIMS applying CVs between $-40 \mathrm{~V}$ and $+30 \mathrm{~V}$, which showed the highest numbers of identified proteoforms in our previous experiment. Analysis of all 16 runs (with and without FAIMS) resulted in 367 protein identifications (Figure 2B) and 1,537 proteoform identifications (Figure 2C). The application of FAIMS resulted in an $8 \%$ increase in proteoform identifications (Figure 2C) and a $62 \%$ increase of protein identifications, with 337 proteins identified with FAIMS compared to 208 proteins identified without FAIMS (Figure 2B). The increase in identifications occurred over the same LC separation conditions and instrument acquisition time.

To characterize the diversity of proteins identified from each replicate with and without FAIMS we generated a heatmap using protein spectral counts (Figure 3A). From eight identical injections without FAIMS, we observed a conserved and stable population of proteins that were detected (Figure 3A). 
In contrast, changing the $\mathrm{CV}$ by $10 \mathrm{~V}$ for each injection resulted in the identification of a fraction of proteins that were unique to each CV (Figure 3A). The CVs with the largest number of new unique IDs were $-40 \mathrm{~V},-30 \mathrm{~V}$, and $-20 \mathrm{~V}$. These results demonstrate that, in TDP experiments, FAIMS can: 1) boost the identification of proteins/proteoforms that would otherwise be not fragmented and identified with only the LC separation alone, and 2) function as a selection filter for the identification of specific proteins/proteoforms from complex samples.

FAIMS improves signal-to-noise by enhancing for the analyte of interest relative to background. Stable ions pass through the FAIMS unit while other ions are deposited onto the FAIMS electrodes. Past experiments with FAIMS would suggest that the identification of new proteins at specific compensation voltages during orthogonal separation might be due to an improvement of signal-to-noise of those proteins 21, 22, 24. To test this possibility, we compared precursor spectra (with or without FAIMS) at retention times where a given protein was only identified by FAIMS. While there were several positive examples throughout the experiment, we focused our analysis on PFR295102 from Arachidonate 5-lipoxygenaseactivating protein (UniProt accession P20292; Figure 3B). At a retention time of 41.57 minutes and a $\mathrm{CV}$ of $-40 \mathrm{~V}$, the dominant $7+$ precursor ion was observed with FAIMS. At the identical retention time (without FAIMS) the precursor ion was not observable above background signal. Fragmentation spectra of the sample that utilized FAIMS showed high quality protein characterization with fragment ions mapping to $52 \%$ of backbone positions (Figure 3C), while no fragment ions were detected in the samples analyzed without FAIMS. Given the importance of Arachidonate 5-lipoxygenase-activating protein in leukotriene synthesis and inflammation ${ }^{31-34}$, the capacity of FAIMS to facilitate characterization of this proteoform and others demonstrates the potential impact of this technique in the analysis of complex biological samples. These results suggest that FAIMS improves the identification and characterization of novel proteins from heterogeneous samples in part through improvement of signal-to-noise ratios of both precursor ions and their fragmentation products. 
Aiming to understand the effect of carrier gas flow on protein and proteoform fractionation in the FAIMS Pro device, we replicated the 8 injections with FAIMS using CVs from $-40 \mathrm{~V}$ to $+30 \mathrm{~V}$ and applied a supplementary carrier gas flow of $1 \mathrm{~L} / \mathrm{min}$. Using these conditions, we identified 212 proteins and 704 proteoforms, representing a decrease of $37 \%$ and $32 \%$, respectively, in the number of identifications compared to the analysis performed without supplemental gas. The use of $1 \mathrm{~L} / \mathrm{min}$. of carrier gas resulted in reduced overall ion signal, suggesting a lower sensitivity under these conditions. Plotting the molecular weight of the identified proteoforms in each CV we observed an inter-relationship between them (Figure 4A). The coefficient of correlation $\left(\mathrm{R}^{2}\right)$ between $\mathrm{CV}$ and molecular weight at $1 \mathrm{~L} / \mathrm{min}$. carrier gas levels was 0.60 and without supplementary carrier gas flow was 0.49 (Figure 4B). These results show that when the cylindrical FAIMS is operated at higher gas levels, overall sensitivity is reduced while selectivity of proteoforms by mass is improved. Hence the elevated gas modes might benefit targeted TDP analysis rather than discovery modes. These results highlight the efficacy of cylindrical FAIMS as a mass selection filter in TDP acquisitions and opens a new range of possibilities for the field.

\section{CONCLUSION}

The FAIMS Pro interface coupled to high resolution MS after reversed-phase LC increased the number of protein and proteoform identifications in TDP experiments performed on 0-30 kDa protein mixtures derived from human $\mathrm{CD}^{+} \mathrm{T}$ cells. The multi-dimensional LC-FAIMS separation occurred over the same instrument acquisition time as samples employing LC-MS alone, but resulted in 62\% more protein identifications. Additionally, through modification of carrier gas flow and CV, FAIMS can function as an effective molecular weight filter for proteoforms, providing a mechanism for predictive selectivity of targets from complex samples. Ultimately, FAIMS improvements are attributable to improved signalto-noise ratios, resulting in the identification of proteoforms in samples that have coeluting species and highly complex matrices. The use of FAIMS in the TDP field will help to achieve deeper proteome characterizations in both discovery and targeted modes of operation. 


\section{AUTHOR INFORMATION}

\section{Corresponding Author}

*Email: n-kelleher@northwestern.edu

\section{Author Contributions}

VRG, RDM, JPD, PMT, NLK contributed to plan the experiments, generating the figures, and writing of the paper. VRG, SA, RDM, DD performed experiments and/or analyzed the data. SA, RH, and MB supported and helped to design the project. The manuscript was written through contributions of all authors. All authors have given approval to the final version of the manuscript. $\$$ These authors contributed equally.

\section{Notes}

NLK consults for Thermo Fisher Scientific. MB and RH are employees of Thermo Fisher Scientific.

\section{ACKNOWLEDGMENTS}

This research was conducted as part of the National Resource for Translational and Developmental Proteomics under Grant P41 GM108569 from the National Institute of General Medical Sciences (NLK).

\section{REFERENCES}

1. Zhang, Y.; Fonslow, B. R.; Shan, B.; Baek, M. C.; Yates, J. R., 3rd, Protein analysis by shotgun/bottom-up proteomics. Chem Rev 2013, 113 (4), 2343-94.

2. Cox, J.; Mann, M., Quantitative, high-resolution proteomics for data-driven systems biology. Annu Rev Biochem 2011, 80, 273-99.

3. Tran, J. C.; Zamdborg, L.; Ahlf, D. R.; Lee, J. E.; Catherman, A. D.; Durbin, K. R.; Tipton, J. D.; Vellaichamy, A.; Kellie, J. F.; Li, M.; Wu, C.; Sweet, S. M.; Early, B. P.; Siuti, N.; LeDuc, R. D.; Compton, P. D.; Thomas, P. M.; Kelleher, N. L., Mapping intact protein isoforms in discovery mode using top-down proteomics. Nature 2011, 480 (7376), 254-8.

4. Zhang, X.; Fang, A.; Riley, C. P.; Wang, M.; Regnier, F. E.; Buck, C., Multi-dimensional liquid chromatography in proteomics--a review. Anal Chim Acta 2010, 664 (2), 101-13.

5. Link, A. J.; Eng, J.; Schieltz, D. M.; Carmack, E.; Mize, G. J.; Morris, D. R.; Garvik, B. M.; Yates, J. R., 3rd, Direct analysis of protein complexes using mass spectrometry. Nat Biotechnol 1999, 17 (7), 676-82.

6. Washburn, M. P.; Wolters, D.; Yates, J. R., 3rd, Large-scale analysis of the yeast proteome by multidimensional protein identification technology. Nat Biotechnol 2001, 19 (3), 242-7. 
7. Cooper, H. J., To What Extent is FAIMS Beneficial in the Analysis of Proteins? J Am Soc Mass Spectrom 2016, 27 (4), 566-77.

8. Guevremont, R., High-field asymmetric waveform ion mobility spectrometry: a new tool for mass spectrometry. J Chromatogr A 2004, 1058 (1-2), 3-19.

9. Shvartsburg, A. A.; Tang, K.; Smith, R. D., Optimization of the design and operation of FAIMS analyzers. J Am Soc Mass Spectrom 2005, 16 (1), 2-12.

10. Swearingen, K. E.; Moritz, R. L., High-field asymmetric waveform ion mobility spectrometry for mass spectrometry-based proteomics. Expert Rev Proteomics 2012, 9 (5), 505-17.

11. Purves, R. W.; Prasad, S.; Belford, M.; Vandenberg, A.; Dunyach, J. J., Optimization of a New Aerodynamic Cylindrical FAIMS Device for Small Molecule Analysis. J Am Soc Mass Spectrom 2017, 28 (3), 525-538.

12. Hebert, A. S.; Prasad, S.; Belford, M. W.; Bailey, D. J.; McAlister, G. C.; Abbatiello, S. E.; Huguet, R.; Wouters, E. R.; Dunyach, J. J.; Brademan, D. R.; Westphall, M. S.; Coon, J. J., Comprehensive Single-Shot Proteomics with FAIMS on a Hybrid Orbitrap Mass Spectrometer. Anal Chem 2018, 90 (15), 9529-9537.

13. Meyer, J. G.; Niemi, N. M.; Pagliarini, D. J.; Coon, J. J., Quantitative shotgun proteome analysis by direct infusion. Nat Methods 2020, 17 (12), 1222-1228.

14. Bonneil, E.; Pfammatter, S.; Thibault, P., Enhancement of mass spectrometry performance for proteomic analyses using high-field asymmetric waveform ion mobility spectrometry (FAIMS). J Mass Spectrom 2015, 50 (11), 1181-95.

15. Saba, J.; Bonneil, E.; Pomies, C.; Eng, K.; Thibault, P., Enhanced sensitivity in proteomics experiments using FAIMS coupled with a hybrid linear ion trap/Orbitrap mass spectrometer. J Proteome Res 2009, 8 (7), 3355-66.

16. Venne, K.; Bonneil, E.; Eng, K.; Thibault, P., Improvement in peptide detection for proteomics analyses using NanoLC-MS and high-field asymmetry waveform ion mobility mass spectrometry. Anal Chem 2005, 77 (7), 2176-86.

17. Koeniger, S. L.; Merenbloom, S. I.; Clemmer, D. E., Evidence for many resolvable structures within conformation types of electrosprayed ubiquitin ions. J Phys Chem B 2006, 110 (13), 7017-21.

18. Laos, V.; Bishop, D.; Lang, C. A.; Marsh, N. M.; Cantrell, K. L.; Buratto, S. K.; Singh, A. K.; Bowers, M. T., Modulating ALS-Related Amyloidogenic TDP-43307-319 Oligomeric Aggregates with Computationally Derived Therapeutic Molecules. Biochemistry 2020, 59 (4), 499-508.

19. Laos, V.; Do, T. D.; Bishop, D.; Jin, Y.; Marsh, N. M.; Quon, B.; Fetters, M.; Cantrell, K. L.; Buratto, S. K.; Bowers, M. T., Characterizing TDP-43307-319 Oligomeric Assembly: Mechanistic and Structural Implications Involved in the Etiology of Amyotrophic Lateral Sclerosis. ACS Chem Neurosci 2019, $10(9), 4112-4123$.

20. Srebalus, C. A.; Li, J.; Marshall, W. S.; Clemmer, D. E., Gas-phase separations of electrosprayed peptide libraries. Anal Chem 1999, 71 (18), 3918-27.

21. Melani, R. D.; Srzentic, K.; Gerbasi, V. R.; McGee, J. P.; Huguet, R.; Fornelli, L.; Kelleher, N. L., Direct measurement of light and heavy antibody chains using ion mobility and middle-down mass spectrometry. MAbs 2019, 11 (8), 1351-1357.

22. Griffiths, R. L.; Cooper, H. J., Direct Tissue Profiling of Protein Complexes: Toward Native Mass Spectrometry Imaging. Anal Chem 2016, 88 (1), 606-9.

23. Griffiths, R. L.; Creese, A. J.; Race, A. M.; Bunch, J.; Cooper, H. J., LESA FAIMS Mass Spectrometry for the Spatial Profiling of Proteins from Tissue. Anal Chem 2016, 88 (13), 6758-66.

24. Griffiths, R. L.; Hughes, J. W.; Abbatiello, S. E.; Belford, M. W.; Styles, I. B.; Cooper, H. J., Comprehensive LESA Mass Spectrometry Imaging of Intact Proteins by Integration of Cylindrical FAIMS. Anal Chem 2020, 92 (4), 2885-2890.

25. Griffiths, R. L.; Kocurek, K. I.; Cooper, H. J., Liquid Extraction Surface Analysis (LESA) HighField Asymmetric Waveform Ion Mobility Spectrometry (FAIMS) Mass Spectrometry for In Situ Analysis of Intact Proteins. Methods Mol Biol 2020, 2084, 191-201. 
26. Sarsby, J.; Griffiths, R. L.; Race, A. M.; Bunch, J.; Randall, E. C.; Creese, A. J.; Cooper, H. J., Liquid Extraction Surface Analysis Mass Spectrometry Coupled with Field Asymmetric Waveform Ion Mobility Spectrometry for Analysis of Intact Proteins from Biological Substrates. Anal Chem 2015, 87 (13), 6794-800.

27. Toby, T. K.; Fornelli, L.; Srzentic, K.; DeHart, C. J.; Levitsky, J.; Friedewald, J.; Kelleher, N. L., A comprehensive pipeline for translational top-down proteomics from a single blood draw. Nat Protoc 2019, 14 (1), 119-152.

28. LeDuc, R. D.; Fellers, R. T.; Early, B. P.; Greer, J. B.; Thomas, P. M.; Kelleher, N. L., The Cscore: a Bayesian framework to sharply improve proteoform scoring in high-throughput top down proteomics. J Proteome Res 2014, 13 (7), 3231-40.

29. Eisen, M. B.; Spellman, P. T.; Brown, P. O.; Botstein, D., Cluster analysis and display of genomewide expression patterns. Proc Natl Acad Sci U S A 1998, 95 (25), 14863-8.

30. Donnelly, D. P.; Rawlins, C. M.; DeHart, C. J.; Fornelli, L.; Schachner, L. F.; Lin, Z.; Lippens, J. L.; Aluri, K. C.; Sarin, R.; Chen, B.; Lantz, C.; Jung, W.; Johnson, K. R.; Koller, A.; Wolff, J. J.; Campuzano, I. D. G.; Auclair, J. R.; Ivanov, A. R.; Whitelegge, J. P.; Pasa-Tolic, L.; Chamot-Rooke, J.; Danis, P. O.; Smith, L. M.; Tsybin, Y. O.; Loo, J. A.; Ge, Y.; Kelleher, N. L.; Agar, J. N., Best practices and benchmarks for intact protein analysis for top-down mass spectrometry. Nat Methods 2019, $16(7), 587-594$.

31. Goodarzi, K.; Goodarzi, M.; Tager, A. M.; Luster, A. D.; von Andrian, U. H., Leukotriene B4 and BLT1 control cytotoxic effector T cell recruitment to inflamed tissues. Nat Immunol 2003, 4 (10), 965-73.

32. Matsumoto, T.; Funk, C. D.; Radmark, O.; Hoog, J. O.; Jornvall, H.; Samuelsson, B., Molecular cloning and amino acid sequence of human 5-lipoxygenase. Proc Natl Acad Sci U S A 1988, 85 (1), 2630 .

33. Ott, V. L.; Cambier, J. C.; Kappler, J.; Marrack, P.; Swanson, B. J., Mast cell-dependent migration of effector CD8+ T cells through production of leukotriene B4. Nat Immunol 2003, 4 (10), 97481.

34. Tager, A. M.; Bromley, S. K.; Medoff, B. D.; Islam, S. A.; Bercury, S. D.; Friedrich, E. B.; Carafone, A. D.; Gerszten, R. E.; Luster, A. D., Leukotriene B4 receptor BLT1 mediates early effector T cell recruitment. Nat Immunol 2003, 4 (10), 982-90. 
Table of Contents (TOC)/Abstract Graphic

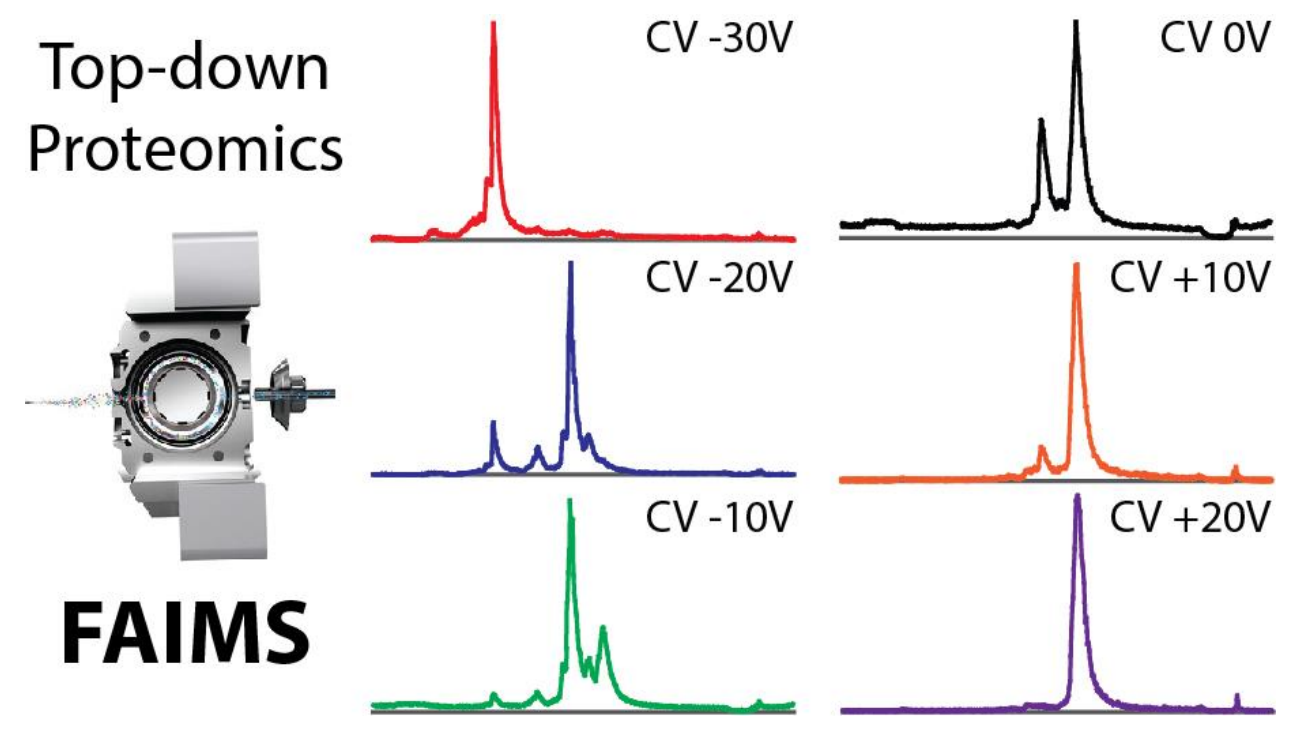




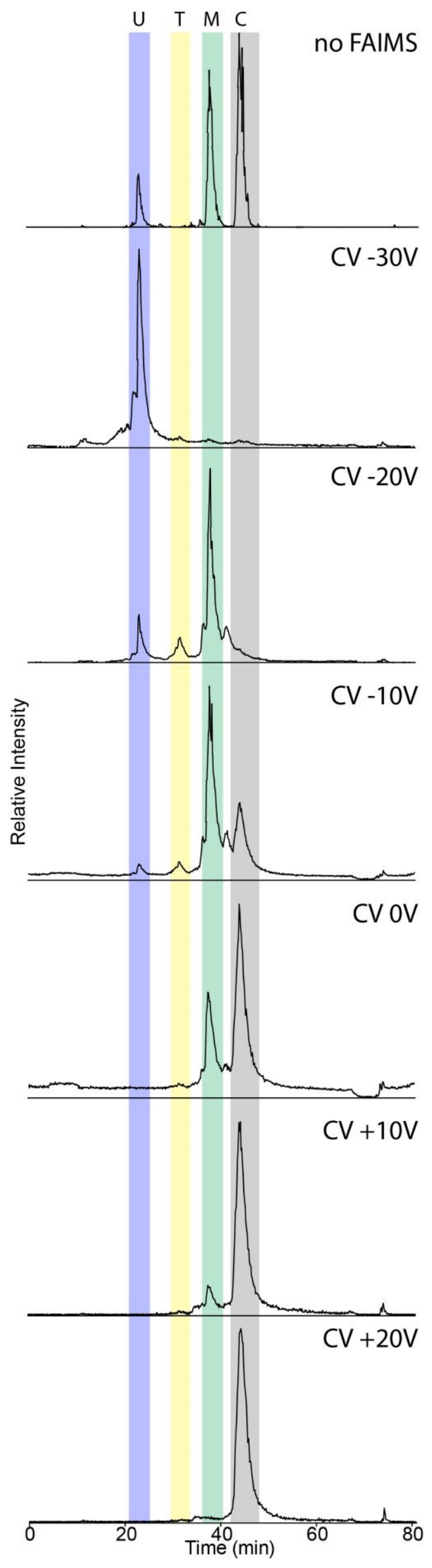


Figure 1: Total ion chromatograms (TICs) of top-down standards using either FAIMS at different CVs or no FAIMS. Top-down standards run without FAIMS (top panel) and with FAIMS using compensation voltages $(\mathrm{CV})$ of $-30 \mathrm{~V},-20 \mathrm{~V},-10 \mathrm{~V}, 0 \mathrm{~V},+10 \mathrm{~V}$, and $+20 \mathrm{~V}$ (lower panels). Top-down standard proteins: ubiquitin, $8.6 \mathrm{kDa}(\mathrm{U})$; trypsinogen, $24 \mathrm{kDa}(\mathrm{T})$; myoglobin, $16.7 \mathrm{kDa}(\mathrm{M})$; carbonic anhydrase, $29 \mathrm{kDa}(\mathrm{C})$. 

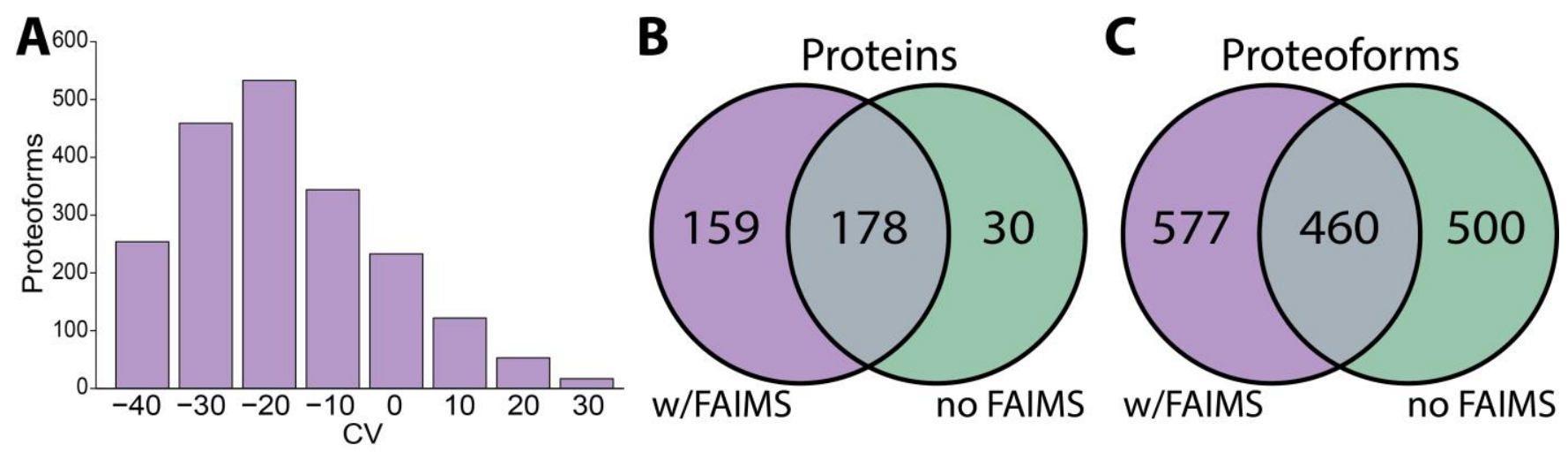

Figure 2: Protein and proteoform identifications with or without FAIMS. (A) Histogram of $C D 3^{+}$ $\mathrm{T}$ cell proteoforms identified at each compensation voltage (CV). Venn diagram of (B) proteins and (C) proteoforms identified from $\mathrm{CD}^{+} \mathrm{T}$ cells subjected to top-down proteomics analysis with FAIMS or without FAIMS. 


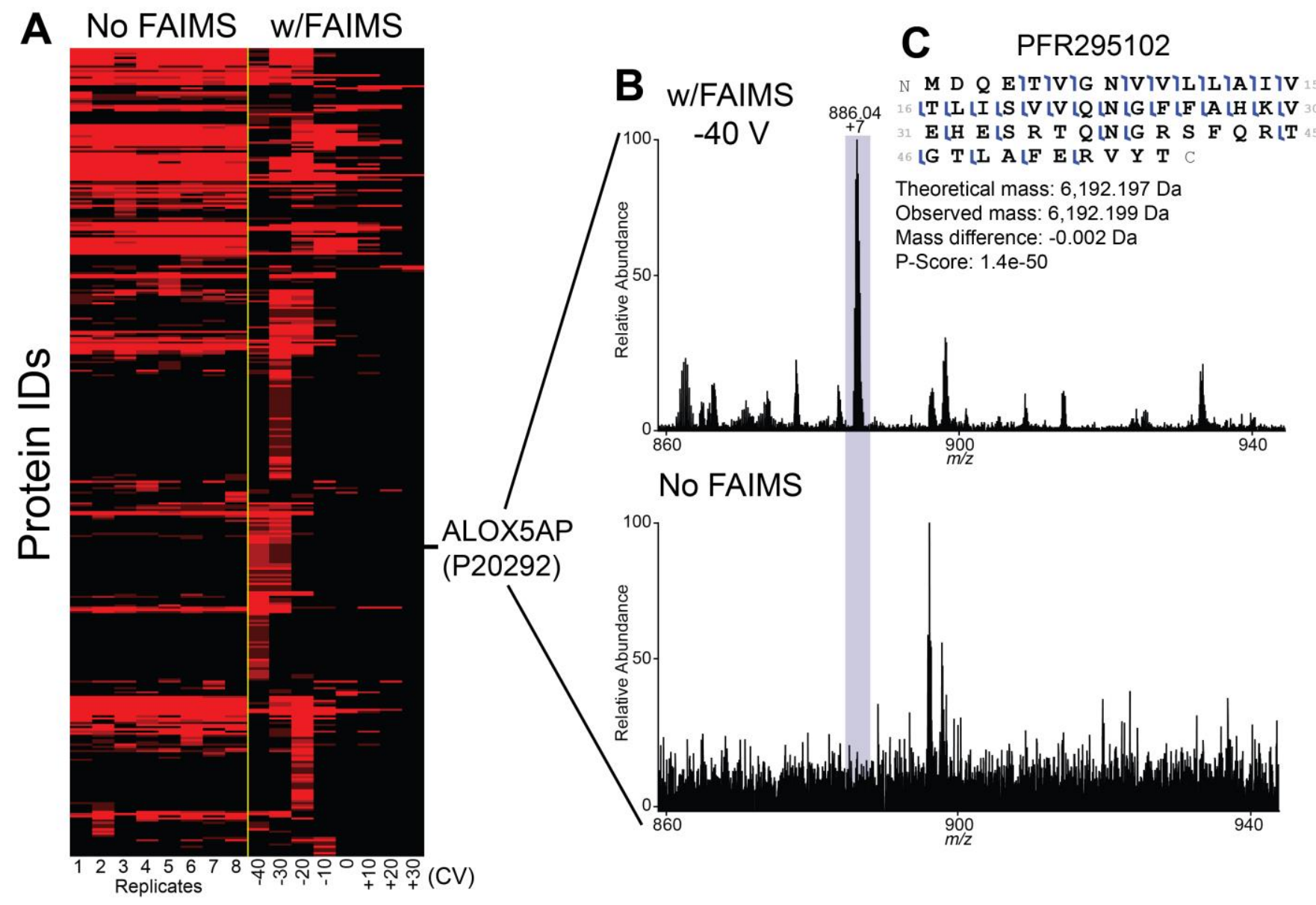

Figure 3. Changing the compensation voltage $(\mathrm{CV})$ results in detection of a hidden population of proteins through improved signal-to-noise. (A) Protein-level heatmap of $\mathrm{CD}^{+} \mathrm{T}$ cell proteins identified without FAIMS (8 technical replicates) or with FAIMS applying different CVs from $-40 \mathrm{~V}$ to $+30 \mathrm{~V}$. CVs for injections analyzed with FAIMS are indicated at the bottom of the heatmap. (B) Mass spectrum of proteoform PFR295102 from UniProt accession P20292 (Arachidonate 5-lipoxygenase-activating protein) analyzed with FAIMS (top panel) and without FAIMS (lower panel) at same retention time. (C) Fragmentation map of PFR295102 showing 52\% sequence coverage in the sample using FAIMS. 

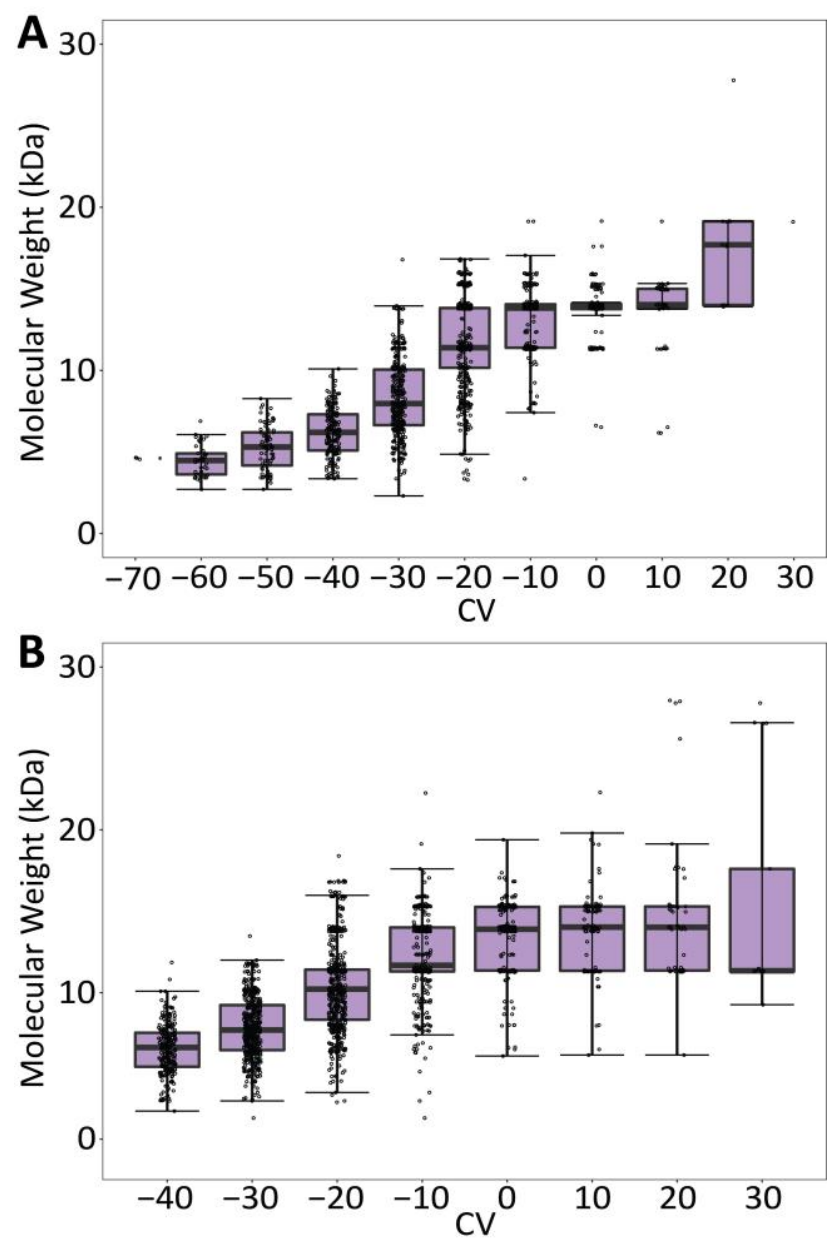

Figure 4. Effect of compensation voltage and gas levels on proteoform fractionation when using FAIMS to separate human $\mathrm{CD3}^{+} \mathbf{T}$ cell proteins. Box and whisker plot of proteoform molecular weight (MW) vs. compensation voltage $(\mathrm{CV})$ when proteoforms are fractionated $(\mathrm{A})$ in the presence of $1 \mathrm{~L} / \mathrm{min}$ of supplemental carrier gas or (B) without supplemental carrier gas. 